
https://doi.org/10.30534/ijeter/2021/09942021

\title{
Fabrication and Development of Portable 3-Axis Computer Numerical Control Machine
}

\author{
Zelalem Weyuma $^{1}$, Ajeet Kumar ${ }^{2}$ and Mukesh Kumar ${ }^{3}$ \\ Lecturer $^{1,3}$, Assosa University, Assosa, Ethiopia, zobeti12@ gmail.com ${ }^{1}$, kumarmukesh.eck@ gmail.com ${ }^{3}$ \\ Assistant Professor ${ }^{2}$, Guru Nanak Institution Technical Campus, Hyderabad, India, ajeetky22@ gmail.com²
}

\begin{abstract}
Machining is a prerequisite fundamental process of manufacturing without which no production can be deemed possible. Conventional machining methods were tedious, costly, time and space consuming, as well as inefficient. With development of computer and numerical control, modern day machining devices have been developed which have made the process a smooth ride. The machining processes are now controllable with the finest accuracies and save time and cost. CNC machines have been the most useful developments that have contributed to the modern day machining task. Computed Numerical Control has thus been our inspiration. This lead us to conceiving and fabricating a 3axis CNC machine that is designed as a router but could perform several operations such as drilling, cutting, printing, milling etc. on attachment of different tools.

The machine has a main driving mechanical subsystem that drives the tool through lead screws attached to motors that are driven by a microcontroller that is under our control through a computer. Any design can be drawn and fed to the Arduino microcontroller from across the world through a Java applet and the machining proceeds by calculating the coordinates of the three axes and the relative movement between the points whose combination is actually the design. The process is thus very accurate and versatile. The fabrication has been achieved by using simple and cheap materials and done in the mechanical workshop located inside the campus.
\end{abstract}

Key words: Stepper motor, spindle motor, lead screw, ball bearings, flexible coupling, and control system by Arduino micro controller.

\section{INTRODUCTION}

CNC machining is a process used in the manufacturing sector that involves the use of computers to control machine tools. Tools that can be controlled in this manner include lathes, mills, routers and grinders. The $\mathrm{CNC}$ in $\mathrm{CNC}$ Machining stands for Computer Numerical Control. Under CNC machining, machine tools function through numerical control. A computer program is customized for an object and the machines are programmed with CNC machining language (called G-code) that essentially controls all features like feed rate, coordination, location and speeds. With CNC machining, the computer can control exact positioning and velocity. CNC machining is used in manufacturing both metal and plastic parts. First a CAD drawing is created (either 2D or 3D), and then a code is created that the CNC machine will understand. The program is loaded and finally an operator runs a test of the program to ensure there are no problems. This trial run is referred to as "cutting air" and it is an important step because any mistake with speed and tool position could result in a scraped part or a damaged machine. There are many advantages to using CNC Machining. The process is more precise than manual machining, and can be repeated in exactly the same manner over and over again. Because of the precision possible with $\mathrm{CNC}$ Machining, this process can produce complex shapes that would be almost impossible to achieve with manual machining. CNC Machining is used in the production of many complex three-dimensional shapes. It is because of these qualities that CNC Machining is used in jobs that need a high level of precision or very repetitive tasks.

\section{LITERATURE REVIEW}

For several years, rigorous research has been conducted in the area of CNC milling from diverse perspectives (Paulo, Rogério and Maria, 2010). Some investigators seem to contribute to the expansion of the frontier of CNC milling knowledge by focusing on system performance improvement tools such as sensors (Sergej .N. Gregoriev, Georgi .M. Martinov, 2016), neural and adaptive networks as well as fuzzy controllers (Phyo Wai Lin, 2018). Others applied optimization techniques to achieve their goals in 
CNC milling research (Rajendra rajput et al (2016),). Still, others have focused on different aspects such as hardenability ( El-bestawi et al., 1997), nano surface generation (X. Xu, Y. Li, J. Sun and S. Wang), new material study (Sharman et al., 2001), free-from surface studies (Terrier et al., 2004), carbon steels (Rajendra rajput et al (2016), and tool life (Sergej .N. Gregoriev, Georgi .M. Martinov, 2016), thus the paragraphs follow contain a comprehensive review of existing studies in the literature in its disicive modes, covering the various contributions of the authors till date. The research paper by Paulo, Rogério and Maria, 2010, studied optimization of CNC milling process parameters using PCAbased Taguchi method that had 35 served the purpose of optimization but not simultaneous optimization of surface roughness and the material removal rate in the study. S.W. Jang had given the outline of the soft material milling parameters in their study on optimization of CNC end-milling of UNS C34000 mediumleaded brass with multiple-surface roughness characteristics. A single-response study provided base in determining the parameters that were studied. The case studies conducted at the laboratory have prompted for the real-time studies and to find the solution for the manufacturing firms around the place. Phyo Wai Lin, 2018 analyzed the effect of the length and diameter of work piece, depth-of-cut and feed while the cutting speed, which is an important machining parameter, was kept constant. Taguchi method was used in this work in order to obtain more reliable and optimum results. Phyo Wai Lin, 2018 criticized the excessive use of high-speed milling for precision machining of aluminium and magnesium and more frequently used results in high quality of the surface and shorter machining times by omitting grinding. Paulo, Rogério and Maria, 2010 highlighted the optimization of the surface roughness when milling aluminum alloys (AA6061-T6) with carbide coated inserts using response surface method (RSM) and Radian Basis Function Network (RBFN) to predict thrust force and surface roughness. Sutraman, Haryono Edi Hermawan, Sarmidi brought out the influence of cutter geometry and cutting parameters during end-milling on the surface texture of aluminum alloy 5083 that was experimentally investigated using Taguchi L18 standard orthogonal array. X. $\mathrm{Xu}, \mathrm{Y}$. Li, J. Sun and S. Wang presented the fact that the extensive research has been conducted in the past on tool flank wear and crater wear in high-speed machining by investigating the effect of tool edge wear on the cutting forces and vibrations in $3 \mathrm{D}$ high-speed finish turning of nickel-based super alloy Inconel 718. Paulo, Rogério and Maria compiled the case study of high-speed milling of titanium alloys and provided base for different metallurgical and machining conditions to be taken into account for 36 the study. The case study of titanium based alloys were conducted for the high-speed milling process for sets of input parameters with moderate cutting speeds and feed rate to get better material removal of aircraft materials.

\section{WORKING}

The CNC machine is a system that is able to accept numerical control inputs to machine a part specified by the exact positioning of the inputs. The machine is able to accept commands through a directly connected personal computer. The personal computer is allowed communication to the main controller subsystem through a USB. The main controller subsystem is able to interpret and communicate the limits of any job, and it can directly control movement of the attachable tool heads. The design to be made can be uploaded through a Java applet from anywhere across the world and will be communicated to the Arduino microcontroller which provides input to the motor drivers connected to the four motors attached to the four lead screws which cause the motion. The framework of the system is the mechanical subsystem which allows for the movement in the $\mathrm{x}, \mathrm{y}, \mathrm{z}$ axes and specify spatial limitations of any acceptable job. The main controller and mechanical subsystems are able to interact through power provided by the motor driver subsystem. The motor driver subsystem will contain a power supply that can accept input power through an electrical outlet plug-in, provide movement independently to the $\mathrm{x}, \mathrm{y}, \mathrm{z}$ axes, and can add an extra board to power the acceleration axis.

\section{MECHANICAL SUBSYSTEM}

It is the machine tool of CNC machine which actually performs machining operation. In our machine tool we have provided 3 axes for providing motion in $\mathrm{x}, \mathrm{y}$ and $\mathrm{z}$ directions.

Motion in all three axes is provided by use of different general use mechanical parts such as bearings, cylindrical rods, square hollow pipes, etc.

Length of CNC machine: $1000 \mathrm{~mm}$

Width of CNC machine: $750 \mathrm{~mm}$

Height of CNC machine: $1000 \mathrm{~mm}$

Various mechanical parts of CNC machine are:

1. Base 
2. X-axis drive system

3. $\mathrm{Y}$ - axis drive system

4. Z- axis drive system

\subsection{Base}

Wooden base is provided in this CNC machine. Dimensions of used wooden base are $1000 \mathrm{~mm} \mathrm{x}$ $750 \mathrm{~mm}$ x $30 \mathrm{~mm}$.

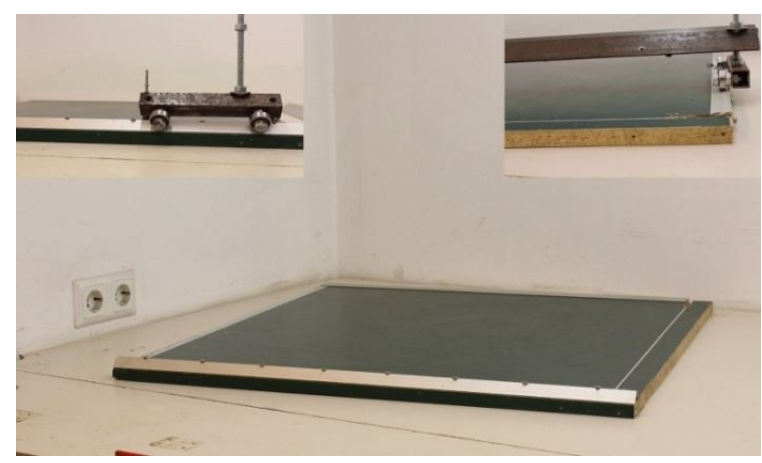

Figure 1 Base of CNC machine

\subsection{X-Axis drive system}

For moving the machine in $\mathrm{X}$ direction, 2 motors with 2 lead screws are provided on both longer sides of wooden board.

Left lead screw is attached to a square pipe of mild steel which has 4 bearings attached to it. These bearings roll on the aluminum angle for providing motion from left side. Similarly, right lead screw is attached to a square pipe of mild steel which has 2 bearings attached to it. These bearings roll on the aluminum angle for providing motion from right side. Dimensions of different parts used in these sub assemblies are: Mild steel square tube: $25 \mathrm{~mm}$ x $25 \mathrm{~mm}$ x 1000 $\mathrm{mm}, 1 \mathrm{~mm}$ thickness Bearings: Ball bearings 10 $\mathrm{mm}$ hole, $30 \mathrm{~mm}$ in total Lead screw: $10 \mathrm{~mm}$ mild steel threaded bar of length $1000 \mathrm{~mm}$ Aluminum angle: profile $20 \mathrm{~mm}$ x $20 \mathrm{~mm}$ x $1000 \mathrm{~mm}, 1 \mathrm{~mm}$ thickness.

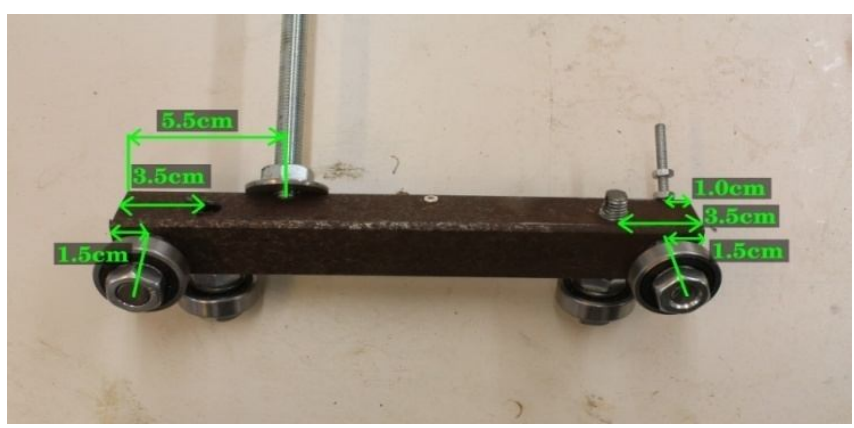

Figure 2 Left subassembly of bar with bearings

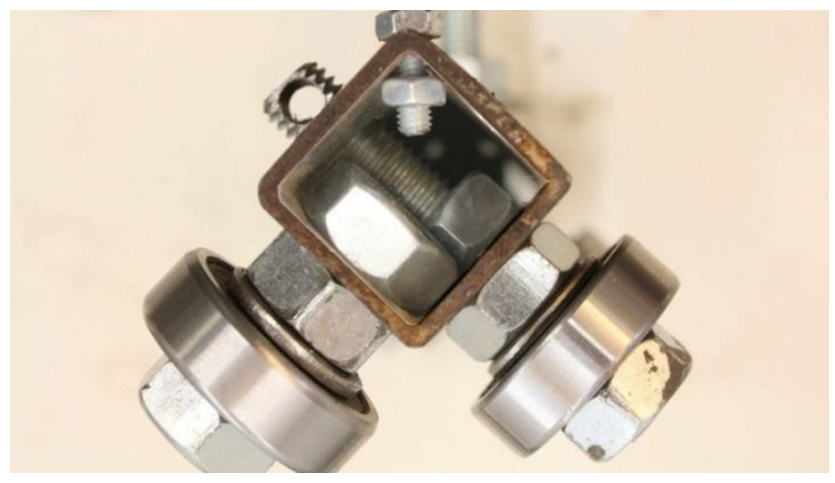

Figure 3 Left subassembly of bar with bearings

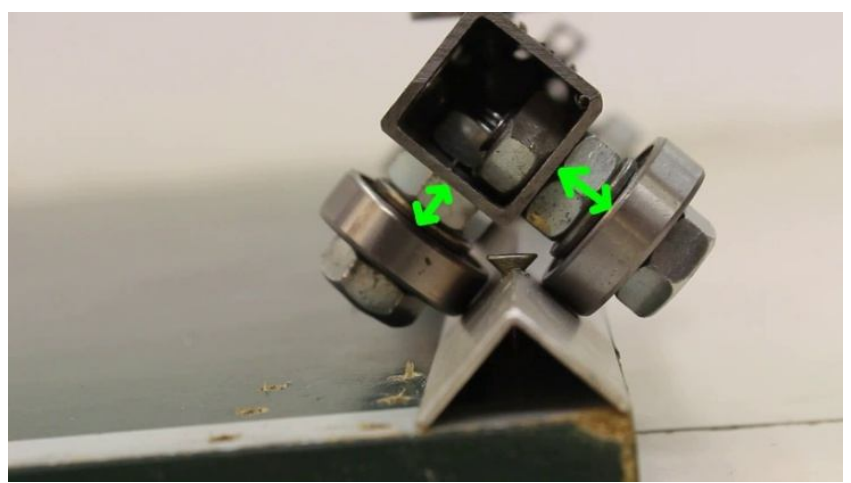

Figure 1 left subassembly of bar with bearings on aluminum angle 


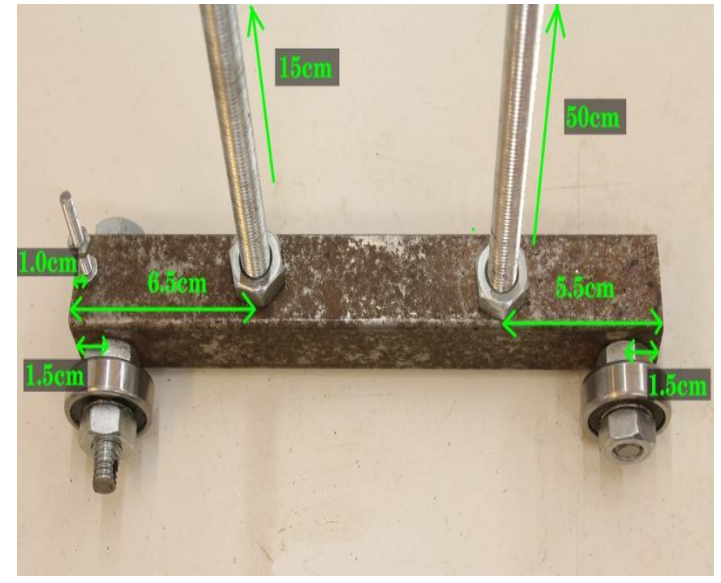

Figure 2 Right subassembly of bar with bearings

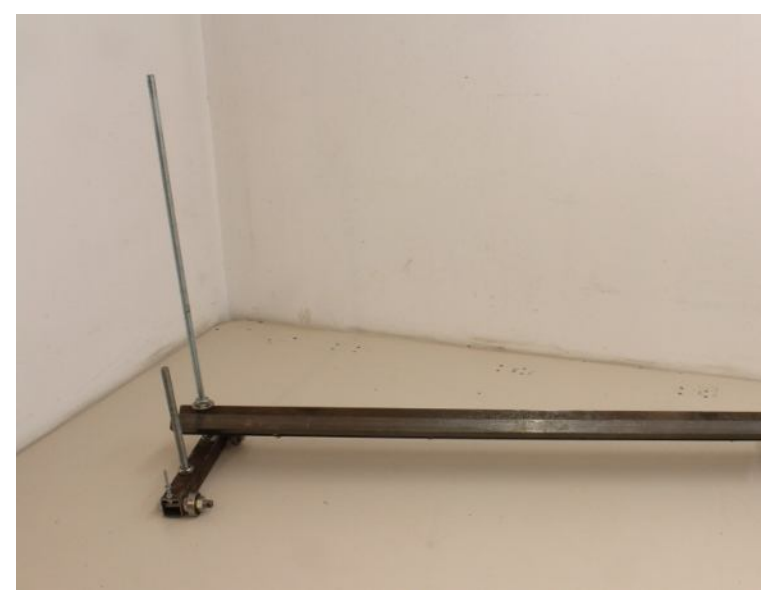

Figure 3 Sub assembly of $x$-axis drive system without lead screws

\subsection{Y-Axis drive systems}

For moving the machine in $\mathrm{Y}$ direction one motor with lead screw is provided. This lead screw is further attached with mild steel square tube which is assembled with 4 bearings as shown previously in left sub assembly of $x$ - axis drive. In this drive, bearings roll on mild steel square tube instead of aluminium angle. Dimensions of different parts used in this sub assembly are:

Mild steel square tube: $25 \mathrm{~mm}$ x $25 \mathrm{~mm}$ x 1000 $\mathrm{mm}, 1 \mathrm{~mm}$ thickness Bearings: Ball bearings 10 $\mathrm{mm}$ hole, $30 \mathrm{~mm}$ in total Lead screw: $10 \mathrm{~mm}$ mild steel threaded bar of length $750 \mathrm{~mm}$ Mild steel square tube: $20 \mathrm{~mm}$ x $20 \mathrm{~mm}$ x $1000 \mathrm{~mm}, 1$ mm thickness.

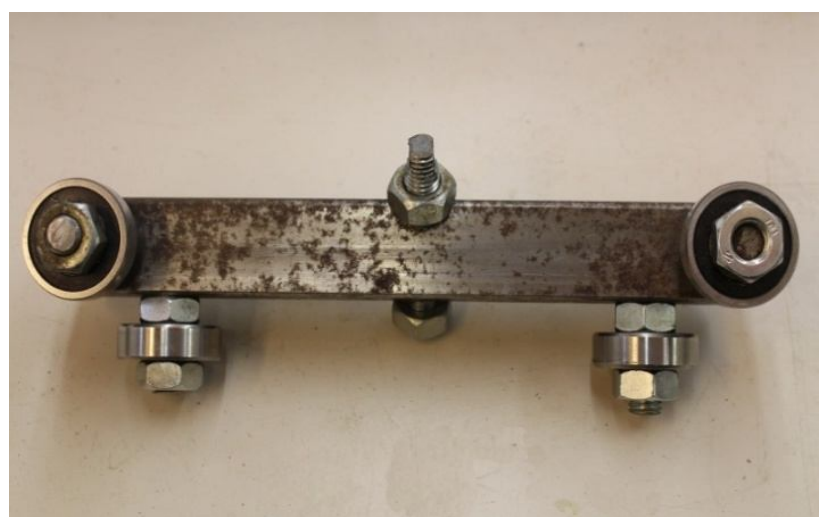

Figure 4 Sub assembly of bar with bearings

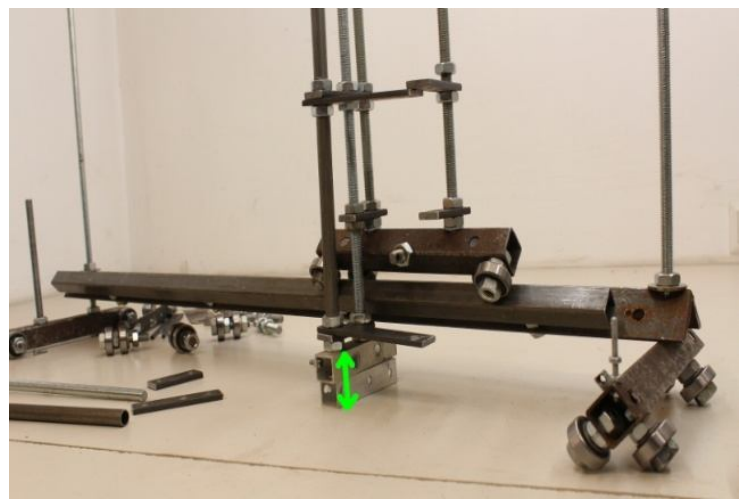

Figure 5 Y-Axis drive system

\subsection{Z-Axis drive system}

For moving machine in $\mathrm{z}$ direction one motor with lead screw is provided. Assembly of 6 round bars (out of which 4 are threaded mild steel bars and 2 are smooth carbide steel bars) are assembled on y-axis drive square tube. In this drive system, 4 bearings are rolled on each carbide steel bar for providing motion in z-axis. Dimensions of parts used in this subassembly are:Threaded bars: $10 \mathrm{~mm}$ dia. mild steel threaded bars of length $750 \mathrm{~mm}$ Carbide steel bars: $10 \mathrm{~mm}$ dia., length $750 \mathrm{~mm}$ Bearings: Ball bearings $10 \mathrm{~mm}$ hole, $30 \mathrm{~mm}$ in total Lead screw: $10 \mathrm{~mm}$ mild steel threaded bar of length $750 \mathrm{~mm}$ 


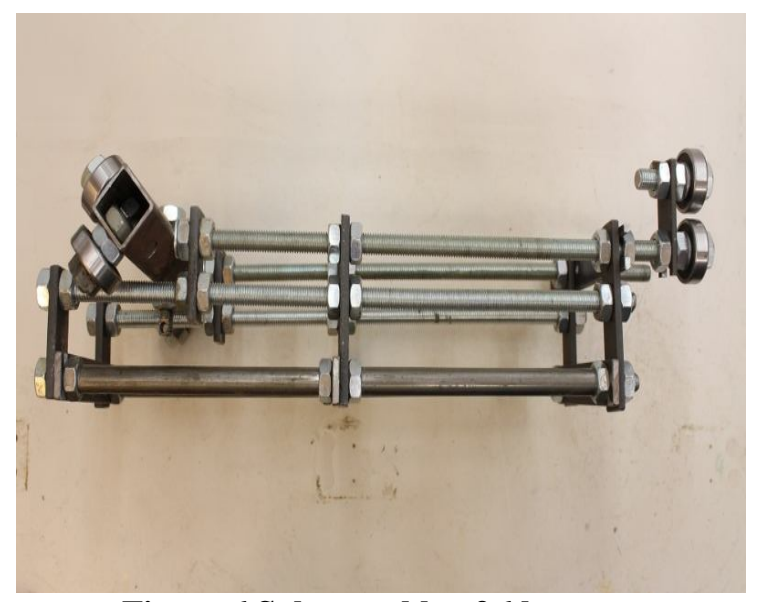

Figure 6 Subassembly of 6 bars

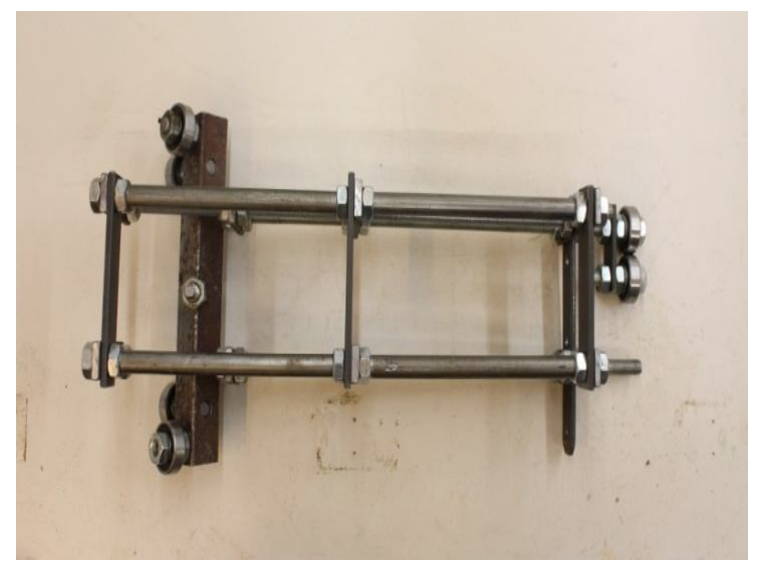

Figure 7 Subassembly of 6 bars

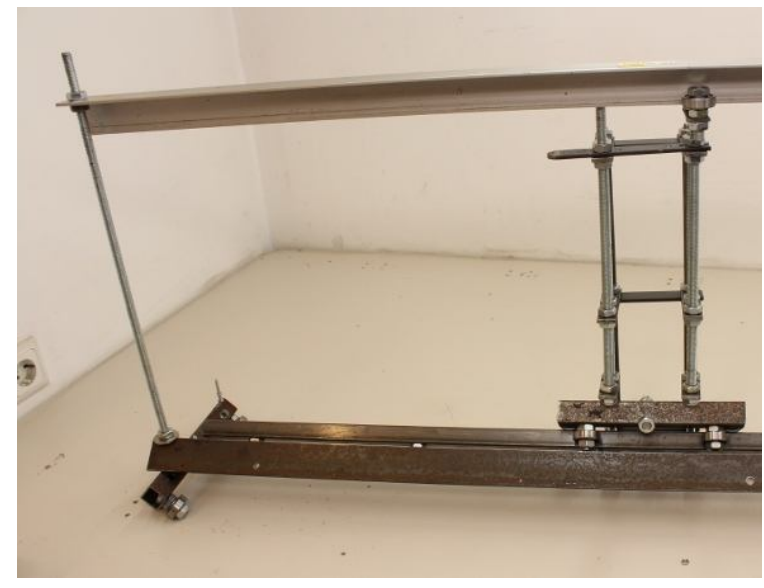

Figure 8 Subassembly of $x, y$ and $z$ axes drive system without lead screw

\section{ELECTRONIC SUB SYSTEM}

It comprises of the microcontroller Arduino, motor driver L293D motor driver and 4 stepper motors as described below.

\subsection{ARDUINO}

Arduino is a software company, project, and user community that designs and microcontrollerbased kits for building digital devices and interactive objects that can sense and control physical devices.

The first Arduino was introduced in 2005, aiming to provide a low cost, easy way for novices and professionals to create devices that interact with their environment using sensors and actuators. Common examples of such devices intended for beginner hobbyists include simple robots, thermostats, and motion detectors.

Arduino boards are available commercially in preassembled form, or as do-it-yourself kits. The hardware design specifications are openly available, allowing the Arduino boards to be produced by anyone. Adafruit Industries estimated in mid-2011 that over 300,000 official Arduinos had been commercially produced, and in 2013 that 700,000 official boards were in users' hands.

\subsection{ARDUINO UNO}

It has 14 digital input/output pins (of which 6 can be used as PWM outputs), 6 analog inputs, a USB connection, a power jack, a reset button and more. It contains everything needed to support the microcontroller; simply connect it to a computer with a USB cable or power it with a AC-to-DC adapter or battery to get started.

There are many varieties of Arduino boards that can be used for different purposes. Some boards look a bit different from the one below, but most Arduinos have the majority of these components in common. 


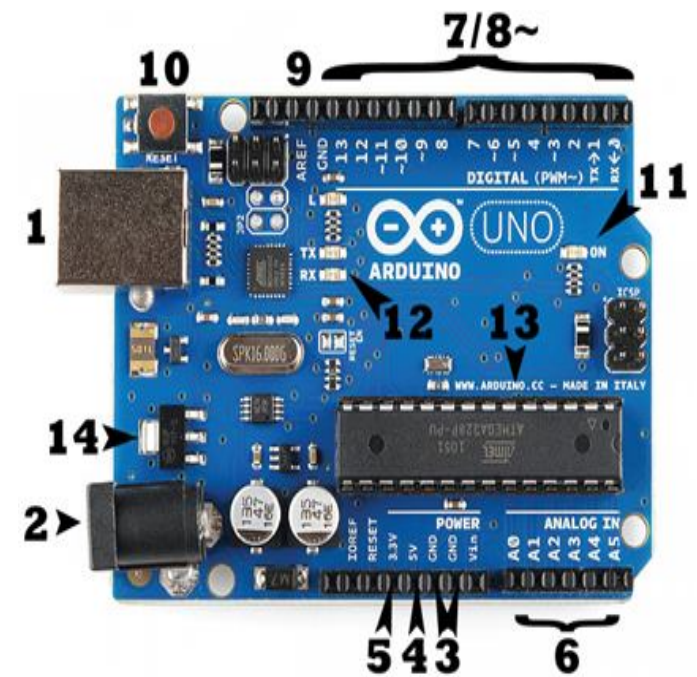

Figure 9 Arduino board

\subsection{Power (USB/barrel jack)}

Every Arduino board needs a way to be connected to a power source. The Arduino UNO can be powered from a USB cable coming from your computer or a wall power supply that is terminated in a barrel jack. In the picture above the USB connection is labeled (1) and the barrel jack is labeled (2).

Table 1 Pin Description

\begin{tabular}{|c|c|c}
\hline Pin No & Function & \\
\hline 1 & Enable pin for Motor 1; active high & \\
\hline 2 & Input 1 for Motor 1 & \\
\hline 3 & Output 1 for Motor 1 & \\
\hline 4 & Ground (0V) & \\
\hline 5 & Ground (0V) & \\
\hline 6 & Input 2 for Motor 1 & \\
\hline 7 & 36V) & \\
\hline 8 & Supply voltage for Motors; $9-12 \mathrm{~V}$ (up to & \\
\hline 9 & Enable pin for Motor 2; active high & \\
\hline 10 & Input 1 for Motor 1 & \\
\hline 11 & Output 1 for Motor 1 & \\
\hline 12 & Ground (0V) & \\
\hline 13 & Ground (0V) & \\
\hline 14 & Output 2 for Motor 1 & \\
\hline 15 & Input2 for Motor 1 & \\
\hline 16 & Supply voltage; 5V (up to 36V) & \\
\hline
\end{tabular}

\subsection{Motor driver L293D}

L293D is a Motor driver integrated circuit which is used to drive DC motors rotating in either direction. It is a 16-pin IC which can control a set of two DC motors simultaneously. The L293D uses 5V for its own power and external power source is needed to drive the motors, which can be up to $36 \mathrm{~V}$ and draw up to $600 \mathrm{~mA}$.

\subsection{Stepper motor}

A stepper motor or step motor or stepping motor is a brushless DC electric motor that divides a full rotation into a number of equal steps. The motor's position can then be commanded to move and hold at one of these steps without any feedback sensor (an open-loop controller), as long as the motor is carefully sized to the application in respect to torque and speed.

The 4 motors used for the project are of $3.3 \mathrm{~V}$ each and have a step angle of 1.5 degrees.

Weight of the motors has been taken into consideration and has kept as low as possible.

\subsection{Final assembly of machine}

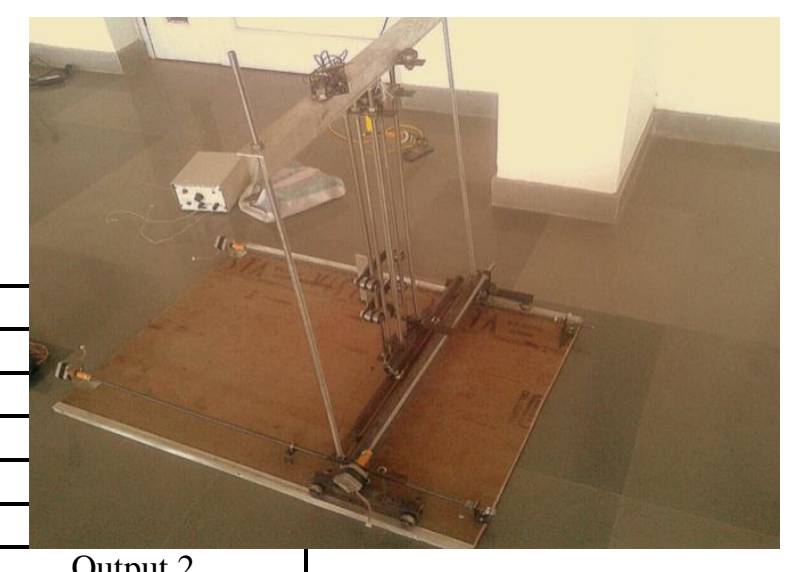

\section{CONCLUSION}

From this project, we learned the principle of CNC machine. We gained better understanding in the modes of operation of CNC machine. There is various type of modern $\mathrm{CNC}$ machines use in industry. The CNC milling can be used for cutting, engraving and marking on plywood, foam board to form 2D and '3D objects. Finally, better and faster control for more intricate designs should be thought of and implemented.

\section{REFERENCES}

1. Sundar pandain et al (2014), demonstrated an open source G-code interpreter i.e. GRBL controller which acts as an inspiration to 
work on the production system with low cost.

2. Dr. J.B. Jayachandraiah et al (2014) provide the idea to develop the low-cost Router system which is capable of 3 Axis simultaneous interpolated.

3. Rajendra rajput et al (2016), demonstrated the comparison of $\mathrm{CNC}$ controller viz., Fanuc 21M 840D, Heidenhain TNC426. Kajal Madekar et al (2016).

4. Venkata Ramesh Mamila, Srinivasulu M, Mani Prasad N, "Study on Computer Numerical Control (CNC) Machines", International Journal of Advanced Scientific Research. Volume 1 - Issue 1, May 2016. pp. 21- 25.

5. Sutraman, Haryono Edi Hermawan, Sarmidi, "Computer Numerical Control (CNC) Milling and Turning for Machining Process in Xintai Indonesia", Journal of Research in Mechanical Engineering. Volume 3 - Issue 5, March 2017. pp. 1-7.
6. Paulo, Rogério and Maria, 2010, "Prototype CNC Machine Design," International Conference on Industry Applications.

7. Sergej .N. Gregoriev, Georgi .M. Martinov, 2016, "Control platform for decomposition and synthesis of specialized CNC system," ELSEVIER.

8. Phyo Wai Lin, 2018, "Design and Fabrication of a Small-scale CNC Milling Machine," International Journal of Scientific \& Engineering Research.

9. X. Xu, Y. Li, J. Sun and S. Wang, -Research and development of open CNC System Based on PC and Motion Controllerll, Procedia Engineering, Volume29, Page No- 1845-1850, 2012.

10. S.W. Jang, "Reseacch for the development of low cost education device using the openning NC system", A Thesis for a Master, Kyeongsang National University, Republic of Korea, (2015). 